Marquette University

e-Publications@Marquette

$1-1-2015$

\title{
After Cassirer: Art and Aesthetic Symbols in Langer and Goodman
}

Curtis L. Carter

Marquette University, curtis.carter@marquette.edu

Published version. "After Cassirer: Art and Aesthetic Symbols in Langer and Goodman," in The Philosophy of Ernst Cassirer: A Novel Assessment. Eds. J Tyler Friedman and Sebastian Luft. Berlin: Walter de Gruyter, 2015: 401-418. DOI. (C) 2015 Walter de Gruyter. Used with permission. 


\section{Curtis L. Carter (Milwaukee)}

After Cassirer:

\section{Art and Aesthetic Symbols in Langer and Goodman}

Throughout the nineteenth century and beyond, both philosophical aesthetics and European and American art underwent significant changes. Just as traditional rationalist philosophical views of how to comprehend the world came unraveled, so a gradual shift in Western art occurred as it moved from the representational styles that had reigned supreme from Classical art and Renaissance art to the modern period. Image making in painting and sculpture, for example, had previously consisted mainly of representing landscapes, portraits, and historical, religious, and mythical subjects. Images in traditional arts also included imaginary subjects such as fairies, and unicorns.

A quotation from Goethe written in 1809 , which comments on the landscape art of Caspar David Friedrich, succintly expresses the relation of art and nature in pre-twentieth century Western art.

An artist who holds fast to nature with earnestness and truth, who unfolds his inner self in his works, and strives toward significance, ... this artist can never lack the support of the public, for he brings new things to light ... and since already in the simple, characteristic, true imitation of Nature an appreciable level of art is attained, there is no reason why the old and tried rules should not be strictly observed. ${ }^{1}$

Viewing Friedrich's drawings from this perspective, Goethe proceeds to illustrate the point in a description of one of Friedrich's drawings viewed in an 1808 Weimar exhibition:

In the first of the four large drawings we see over high hills lit by the rays of the rising sun, and over the tops of dark trees towards the edge of the sea, which, ruffled by a light breeze, is making barely perceptible waves. In the distance rises the steep coastline of an island. On a nearby hill a cross has been erected under tall trees, which bend towards each other to form a natural arch or temple [...]..$^{2}$

While never entirely abandoned in the subsequent history of art, representational art began to give way in the late nineteenth century with the emergence of Im-

1 Goethe (1980), 229.

2 Ibid., 229. 
pressionist painting. Impressionist painting explored perceptual sensations of natural light, atmosphere, and movement while moving away from representation. Textured surfaces consisting of short stiff brush strokes and mixed colors replace the smooth glazed figurative surfaces of traditional paintings.

The new forms of art such as Expressionism and Cubism at the beginnings of the twentieth century focused on the inner forms of feeling and ideas of the individual artist's experiences, or on abstract form. Aesthetic concepts based on rationalist principles positing a correspondence between artists' images and the external worlds of nature and civilization were no longer suited to account for this new art. Empiricism focused on sensations and aimed at describing or analyzing surface perceptual features of art, which proved insufficient for interpreting the broad scope of new art. As it turned out, positivist empiricism had little interest in the arts. Instead, the positivists turned their attention to science and to replacing traditional metaphysics with the development of formal logical or mathematical symbol systems.

Since modern art forms no longer employed representation as the dominant means for art making, it became necessary for aesthetics to search for alternative ways of understanding art. Developments in art were accompanied by efforts of philosophers such as Ernst Cassirer, Susanne Langer, and Nelson Goodman to introduce their respective aesthetic theories featuring symbols. These philosophers base their approaches to art, language, myth, and science on their respective theories of symbols. My presentation here will consist of a brief look at Cassirer's philosophy of symbols as it applies to the arts, and then an examination of how central ideas in Cassirer's thought subsequently took root in the respective aesthetic theories of Suzanne Langer and Nelson Goodman.

\section{Cassirer and Art Symbols}

Basing his philosophy of symbols in part on an understanding of ideas found in the writings of idealist philosophers Vico, Kant, and Hegel, Cassirer set forth his main ideas on the formation of symbols in his three volume The Philosophy of Symbolic Forms, first published respectively in 1923, 1925, and 1929. A fourth volume assembled from Cassirer's unpublished manuscripts by John Michael Krois and Donald Verene was published in $1996{ }^{3}$ This fourth volume is believed by the editors to represent Cassirer's intention to produce a fourth volume. A shorter

3 Cassirer (1996). 
version of his system, An Essay on Man, published in 1944, includes a chapter devoted to art symbols.

Running throughout Cassirer's philosophy is the notion that human experience, and our attendant world or worlds, exists in the form of symbols. Hence, a primary activity of humans is the generation of different forms of symbolism. Among the symbolic forms that Cassirer addresses are language, science, myth, religion, history, and art. He is particularly adamant in the claim that science based on empirical data and logic is only one form of symbolism, and that the other symbolic forms are necessary to a full understanding of the human domain. In other words, empirical data and logic, however useful, are not the measure of all that contributes value and meaning to human life. Hence, the symbolic forms of language, myth and art, as well as religion, history, and technology, provide complementary approaches to our understanding of human life.

Cassirer, in effect, views the metaphysical traditions of rationalist philosophers, who seek to match up a set of rational principles and whatever else there is in their accounts of the world, as yielding unsatisfactory accounts of human life. Similarly, constructed logic, mathematical symbols and empiricism based on sensory data are relegated to a more limited role than their perpetrators have envisioned.

As noted, our main concern here is with Cassirer's treatment of art symbols and its subsequent influence. There is, however, a problem in choosing to focus on Cassirer's art symbols and the aesthetic. He never devotes a volume of his major work, The Philosophy of Symbolic Forms, to art as he does, for example, to myth. Art is thus arguably the least well attended to symbolic form in Cassirer's philosophy.

Our first task then, is to establish the significance of art in Cassirer's treatment of symbols. In addressing this question, it is important to note that art appears in virtually every iteration of the forms of symbols throughout Cassirer's publications. He is unwavering in his inclusion of art among the formative symbols necessary to articulate the human spirit. It appears that art clearly exemplifies the necessary features possessed by other acknowledged symbolic forms such as language, myth, and religion. ${ }^{4}$ In an essay he published in 1930 shortly after the publication of Volume III of The Philosophy of Symbolic Forms, Cassirer affirms Goethe's commentary on the forces of attraction and repulsion concerning art's relation to the world. "There is no surer way of evading the world than

4 Symbolic forms including art share in common two features: they contribute to human understanding and are way of world making. See also Hendel (1955a), 48. 
through art ...." and "There is no surer way of binding oneself to it than through art". ${ }^{5}$

Catherine Gilbert's essay, “Cassirer's Placement of Art”, situates Cassirer's discussion of art symbols in the context of philosophical aesthetics and examines art's place with respect to other symbolic forms. Gilbert also takes note of the absence of a major volume on art in Cassirer's writings, but argues nevertheless that, "The aesthetic symbol [i.e. art] is, then, for Cassirer, symbol at its height". ${ }^{6}$ Harry Slochower echoes this claim when he argues that, "art problems are not simply an integral part of Cassirer's philosophy but the most characteristic amplification of his method and system". ${ }^{7}$ Method here refers to the dialectical interplay in Cassirer's theory of symbols between particulars as in works of art and the functional unity of the whole of the symbolic forms that comprise consciousness.

Current studies on Cassirer's understanding of art symbols continue to affirm the importance of art in his philosophy of symbols. Fabien Capeillères essays on art in Cassirer's thought published in Cassirer Studies I, II, and IV are of particular interest for their treatment of the various problems that arise with respect to Cassirer's views on art and symbolic form. Among the topics being investigated in these volumes: Cassirer's relation to art historical and cultural investigations at the Warburg Institute for Cultural studies and the art historical work of Panofsky (Volume I), an examination of the materials concerning art in the manuscript "K for Kunst" assembled by Krois and Verene as Volume IV of Philosophy of Symbolic Forms (Volume II), and an examination of art critique in reference to philosophy, and its application in Cassirer's aesthetics to art as a field of symbols which participates in world-constructing, versus its application to art as a field of objects. ${ }^{8}$ Capeillères and other current studies concerning Cassirer's views on art symbols are more than sufficient evidence that this topic remains viable for continued investigation.

A letter from Cassirer to Paul Schilpp sent during the preparation of the volume of the Library of Living Philosophers featuring Cassirer might explain in part his failure to produce a volume of The Philosophy of Symbolic Forms dedicated to art. This letter of May 13, 1942 is cited in the introduction of Krois and Verene to their presentation of the previously unpublished Volume IV of The Philosophy of Symbolic Forms. Here, "Cassirer noted that in the first sketch ... of his Philosophy of Symbolic Forms he had considered a volume on art, but the malice (Ungust) of

5 Cassirer (1949), 870.

6 Gilbert, (1949), 609.

7 Slochower (1949), 633.

8 Capeillèrs (2008, 2009, 2011). See also Capeillèrs (2013). 
the times had caused him to put it off again and again". ${ }^{9}$ He stated in the 1942 letter to Schilpp that he now intended to present his aesthetics.

Perhaps this task was begun in the chapter on art in his Essay on Man written during his tenure at Yale University and published in 1944, the year prior to Cassirer's death. In fact, his most extended discussion of art symbols appears as a chapter in this late work. Three unpublished lectures, "Language and Art I", and "Language and Art II", and "The Educational Value of Art" made available in Symbol, Myth, and Culture, a collection of Cassirer's essays and lectures edited by Verene and published in 1979, offer additional comments on art symbols and art. $^{10}$

The overall message seems to be that a well-formed understanding of culture will embrace art and a wide range of symbolic forms. Throughout, his discussion of symbolic forms takes place in a rich context of the history of both philosophy and art. The former is informed by the philosophies of Vico, Kant, and Hegel. The latter is fueled by his engagement with the Warburg Institute and Panofsky's views on art history, as noted by Capeillères.

For Cassirer, art originates in imagination and gives us "the intuition of the form of things ... as a true and genuine discovery". ${ }^{11}$ Art offers a perspective that differs from ordinary seeing as well as from the impoverished abstractions of science based on facts or purported natural laws. Both of these focus on "constant and common features" of things. "Aesthetic perception exhibits a much greater variety and belongs to a much more complex order than our ordinary sense perception". ${ }^{12}$ According to Cassirer "The artistic eye is not a passive eye that receives and registers the impression of things. It is a constructive eye, and it is only by such constructive acts that we can discover the beauty of natural things. Hence, the greatness of an artist is characterized by an ability to "elicit from static materials a dynamic life of forms". ${ }^{13}$ This process depends on "formative acts of contemplation" which differ from the "acts of theoretical objectification, by scientific concepts and constructs". ${ }^{14}$ In effect, art "teaches us to visualize, not merely to conceptualize or utilize things [... ]. Art gives us a richer more vivid

9 Cassirer (1996), xxiii. The letter to Schilpp is in the Library of Living Philosophers Collection at the University of southern Illinois Carbondale.

10 Cassirer (1979a and 1979b)145-195. See also Cassirer (1979c), 208-209, 211-212.

11 Cassirer (1956), 184.

12 Ibid., 185.

13 Ibid., 193.

14 Ibid., 204. 
and colorful image of reality, and a more profound insight into its formal structure". 15

\section{Langer and Cassirer}

Among the philosophers who have continued to explore ideas found in Cassirer's writings on art as a symbolic form is the American philosopher Susanne Langer. Langer is credited as being the most effective in carrying forward aspects of Cassirer's notion of symbolic forms. Langer's interest in Cassirer's ideas extends to both aesthetics and myth, as she translated Cassirer's book on myth as a form of symbolic life. ${ }^{16}$ Here, our discussion will focus on Langer's views of aesthetic symbols. My point will not be to show that Langer simply adopts Cassirer's ideas concerning art symbols. Rather, she takes his core notion of symbolic form and then develops her own contributions to the understanding of art symbols.

Evidence of Langer's connections to Cassirer is found in her various references to his Philosophy of Symbolic Form found throughout her writings. For example, Langer's Philosophy in a New Key (1941) includes five different citations referring to Cassirer. Additional citations of Cassirer appear in Langer's Mind: An Essay on Human Feeling (three volumes: 1967, 1972, and 1982), in Philosophical Sketches (1962) and also in her discussion of Cassirer's views on language and myth.

Perhaps Langer's most explicit commentaries on Cassirer's contributions to philosophy of symbols are found in the essay, "On a New Definition of 'Symbol" published in her Philosophical Sketches, and in a passage found in Mind: An Essay on Human Feeling I, where she discusses the import of art.

It was in reflecting on the nature of art that I came on a conception of the symbol relation quite distinct from the one I had formed in connection with all my earlier studies, which had centered on symbolic logic. This new view of symbolization...had been highly developed in Cassirer's Philosophie der symbolischen Formen. In many years of work on the fundamental problems of art I have found it indispensable. ${ }^{17}$

Langer again affirms her indebtedness to Cassirer's The Philosophy of Symbolic Forms in Mind: An Essay on Human Feeling I, where she acknowledges his "ad-

15 Ibid., 236.

16 Cassirer (1946).

17 Langer (1962a), 58. 
mirable scholarship and awareness of its implications" for differentiating among the different symbolic forms necessary to accommodate different modes of thought. In her words,

Since the publication of that pioneering work [The Philosophy of Symbolic Forms] a number of books and articles have appeared ... but none, so far as I know, has gone on to develop the differences among the forms beyond those, which Cassirer indicated. ${ }^{18}$

Judging from their respective comments on art and symbols, it would appear that Langer and Cassirer are in agreement on many points. They both recognize the importance of acknowledging a range of symbol systems including language, art, myth and symbolic logic, mathematics and the natural sciences. Both agree that the symbols in the respective cultural systems function according to different principles, and contribute in different ways to the creation of human life. Art symbols for Cassirer and Langer are considered generative of aspects of life that go beyond what is received through sense data representing the external world. Hence intuition, feeling, and sensuous form are terms that resonate in the views of both Langer's and Cassirer's views concerning aesthetic symbols.

Langer defines art as "the practice of creating perceptible forms expressive of human feeling", which includes painting, sculpture, architecture, music, dance, literature, drama and film. ${ }^{19}$ She holds the view that, "The primary function of art is to objectify feeling so that we can contemplate and understand it". ${ }^{20}$ Hence, art symbols give access to the inner life not otherwise accessible through symbols used in language, mathematics and the empirical sciences. Form, or 'significant form', as Langer refers to it in Philosophy in a New Key, where she considers form in reference to music, is the means by which art symbols articulate feeling. ${ }^{21}$ "Expression" as used by Langer does not mean the ordinary venting of feelings. Instead, Langer's uses expression to refer to the presentation of an idea of feeling as conveyed by an artistic symbol. Art thus contributes to understanding, albeit not by way of concepts.

Langer would agree with Cassirer's notion that human understanding requires thinking beyond rationalist conceptions of prior developments in philosophy and scientific views of both the external world and human consciousness. In short, both thinkers ask us to abandon chauvinistic claims of science or symbol systems based on symbolic logic to exclusive rights as the measure of all

18 Langer (1967a), 80-81.

19 Langer (1962b), 85.

20 Ibid., 90.

21 Langer (1950). 
human understanding. In doing so, Langer and Cassirer point to a holistic view of reality, which is created out of the available varieties of symbols. This shared holistic view does not assign normative or hierarchical relationships among the various forms of symbols. Rather, it finds value in recognizing the cognitive worth of all the forms of human symbols.

Given this brief exposition of key points in the aesthetics of Langer and Cassirer, it seems that they are in agreement on the central themes in their respective aesthetics. In short, by introducing art into their philosophies of symbolism alongside language, myth and other forms of symbolism, both Langer and Cassirer insure that human beings are not limited to a singular approach to constructing a world view of reality, but can choose a single specific point of view and pass from one aspect of things to another. ${ }^{22}$

\section{Cassirer and Langer on Language and Art}

In order to take a closer view of Langer's relation to Cassirer's views on symbolic forms it will be useful to consider their respective views on language and art. As we have seen, Cassirer's aesthetics emerges from the main currents of the history of philosophy running from Plato through Vico, Kant, Hegel. However, Cassirer's early work was in epistemology, philosophy of science and logic. (There is not time to develop these connections, but the references throughout Cassirer's texts as well as in the interpretations of scholars such as Donald Verene and others will support this claim. $)^{23}$ Langer also began her studies of symbols from her initial work in symbolic logic as noted previously.

However, their views of art emerge from out of different directions. Cassirer's discussion is richly grounded in the history of philosophy, whereas Langer bases much of her study of symbols in biology and psychology. In keeping with his grounding in the history of philosophy, Cassirer's essay on "Language and Art" offers a broad overview of philosophical issues concerning the different uses of language from Plato through Croce. He takes note of the significance of language as a primary form of symbolism and explores its different uses. Among these uses, for example, are ordinary language, poetry, and scientific language. Underlying his argument here is the claim, shared by Langer, that art contributes to cognitive understanding in ways that are not accessible to

22 Cassirer (1956), 217; Langer (1967b), 205-206.

23 Verene (1979), 2. 
non-art symbols, including language. ${ }^{24}$ Cassirer argues that the artist focuses on the pure expressive form of things achieved through creative intuition of the human systems. In other words, art is not comprised of logical propositions or empirical descriptions. This point of view is in contrast to that of the engineer or scientist whose interest lies in empirical facts or the physical qualities of things. ${ }^{25}$

At this point Langer begins her attempt to address more fully the question of the differences between language symbols and art symbols, which she noted that Cassirer had not completed. In her quest to answer the Positivists' neglect or dismissal of art, Langer argues for art's intellectual credibility by giving it a "logic" of its own. Art's logic functions parallel to logic as found in symbolic logic, mathematics, and the languages of the empirical sciences. A remark from chapter four of Philosophy in a New Key suggests that this distinction arises out of a desire to free cognitive activity from a limit, which follows from the post-Wittgensteinian and post-Carnapian analysis of language. ${ }^{26}$

Her solution introduces a distinction between discursive and presentational symbols. Discursive symbols operate in language systems with syntactical and semantic features. Syntax provides construction rules for well-formed units of a language, and semantic rules establish guidelines for creating a vocabulary of meaningful units capable of interpretation such as words that represent objects.

Langer includes art in the category of presentational or non-discursive symbols that do not require syntactic or semantic rules. For example, in the case of a painting:

Visual form-lines, colors, proportion, etc. are just as capable of articulation, i.e. of complex combination as words. But the laws that govern this sort of articulation are altogether different from the laws of syntax that governs language. The most radical difference is that visual forms are not discursive. ${ }^{27}$

The core of Langer's explanation of the logic of art symbols, as she explains in Mind: an Essay on Human Feeling I, lies in the notion that the artist projects the idea of a feeling through the artwork. Projection, as Langer notes, has multiple dimensions as it applies to art symbols. In this case, she intends it to be under-

24 Cassirer (1979a) 145-165. See also Cassirer (1979b), 185-186, for further comments on the relation of art and language.

25 Cassirer (1979a), 159.

26 Langer (1967b), 86, 87.

27 Ibid., 93, 94. 
stood to mean that the expressive object (art) projects or expresses in some perceptible form the artist's idea of feeling, "the symbolization of vital and emotional experience for which verbal discourse is peculiarly unsuited". ${ }^{28}$ Citing Ivy Campbell-Fisher, Langer agrees that the created form in art expresses "the nature of feelings conceived, imaginatively realized, and rendered by a labor of formulation and abstractive vision". ${ }^{29}$

Langer offers in support of her distinction between language and painting these arguments, which we can only summarize here:

a. Presentational symbols (art) express the form of feelings generated by the productive action of the work in expression.

b. Discursive symbols present their constituent elements sequentially, while paintings present theirs simultaneously.

c. Elements in language have fixed meaning, whereas the elements in a painting do not.

d. The rules for combining elements in language are few enough to allow for syntax, and the conventions are more binding than painting. ${ }^{30}$

There is not time to examine Langer 's case for the division of language and art symbols according to discursive versus presentational symbols as I have done elsewhere. ${ }^{31}$ One difficulty is that nowhere in her comparison of the vocabularies that distinguish language and painting does Langer establish what the units of comparison might be.

If, as Langer believed, no one since Cassirer had proceeded beyond what he established to account for the differences among the various forms of symbols, we may acknowledge Langer for undertaking this challenge. It is sufficient to our aims here to note that Langer's differentiation of language and art symbols extends beyond the discussion of the differences among forms of symbols offered by Cassirer. Her solution to the problem seems closer to logical solutions of analytic philosophers such as Carnap than to those likely to be found starting from the metaphysical sources found in the historical authors (Vico, Kant, Hegel) as understood by Cassirer.

28 Langer (1967a), 80.

29 Ibid., 90.

30 A fuller development of Langer's argument appears in ibid., 90, 102.

31 Carter (1974). 


\section{Goodman and Cassirer}

After Cassirer and Langer, Nelson Goodman (1906-1998), is arguably the philosopher to pay most attention to art symbols. Goodman thought of his work as belonging to the main stream of philosophy, but on his own constructed path. In this respect, he proposed to substitute his constructed symbol systems for the structures of the world, mind, and concepts. According to Goodman, the symbol systems of the sciences, philosophy, perception, the arts, as well as everyday discourse, constitute ways of world making. The Structure of Appearance, Goodman's first major book, reaches back to Carnap's Aufbau (The Logical Structure of The World) and offers a general theory of the systematic logical experience and actual construction of specific symbol systems. In The Structure of Appearances, Goodman follows Carnap in recognizing a plurality of logics and languages whose rules are fixed by convention instead of by one universal logic. ${ }^{32}$

Goodman's main connections to Cassirer are acknowledged in the first chapter of his 1978 book, Ways of Worldmaking where he offers a warm tribute to Cassirer's philosophy of symbols. Languages of Art also contain a reference to Cassirer's Philosophy of Symbolic Forms II in conjunction with their respective discussions of metaphor. A third reference to Cassirer can be found in a supplementary reading list to Chapter 3 of Problems and Projects. ${ }^{33}$ In Ways of Worldmaking, Goodman cites as common themes shared with Cassirer, "... The multiplicity of worlds, the speciousness of 'the given', the creative power of the understanding, the variety and formative function of symbols" as being integral to his own thinking. Goodman's aim is to explore further such questions as these: "In just what sense are there many worlds? What distinguishes genuine from spurious worlds? ... What role do symbols play in the making? And how is world making related to knowledge?" ${ }^{34}$ The task of exploring these themes in depth would be well beyond the scope of this essay, but I will bring to light

32 Goodman, (1951), $114 \mathrm{ff}$.

33 Goodman (1978a). This first chapter of Ways of World-making was read at the University of Hamburg on the $100^{\text {th }}$ anniversary of the birth of Ernst Cassirer. See also, Goodman (1978b), 77; Goodman (1972), 147.

34 Goodman (1978a), 1. In this passage Goodman appears to attribute the theory of multiple worlds to Cassirer. However there is some question as to whether Cassirer understands multiple worlds in the same sense as Goodman who clearly holds to a plurality of worlds or world versions. Cassirer seems to entertain a holistic view in which multiple worlds are in some sense reconciled. This is a point for further investigation. Goodman's multiple worlds are perhaps linked together in the sense that each correct multiple world may contribute to understanding. The test of a multiple world version is its cognitive effectiveness. See Scheffler (1985). 
here a brief exposition of Goodman's treatment of art symbols in order to show in parallel how his views complement, or go beyond those of Cassirer and Langer.

In Languages of Art (1968) Goodman presents his theory of art symbols in the context of a more general theory of symbols. Through careful individuation of the different kinds of symbolism represented in painting, music, dance, literature and the other arts, he offers a fresh structure for addressing key problems in aesthetics. His theory of art and other forms of symbols is based on the view that the use of symbols beyond immediate practical needs is for the sake of understanding or "cognition in and for itself". Understanding draws upon the urge to know or delight in discovery, and leads to enlightenment. The uses of symbols for communication and other practical or pleasurable uses are secondary. The criteria for judging symbols, whether in the sciences or the arts, depend on how well a symbol serves its cognitive purposes: "how it analyzes, sorts, orders, and organizes", and how the symbols participate in the making and transformation of knowledge..$^{35}$

In an effort to show how pictures, music and dance performances, literary texts and buildings shape our experience as partners of the sciences, Goodman analyzes the various art forms with respect to semantic and syntactic differences. Here, he offers an alternative to Langer's claim that the arts lack syntax and semantics, which she allows only for language as a discursive symbol system. (As noted previously, Langer assigns the arts to a category of presentational symbols with their own non-discursive symbolic features.) For example, according to Goodman, paintings are considered syntactically dense symbols due to the inability ability to differentiate characters in the compositional schemes (shapes, brush marks etc.) of the works. Whereas, music allows for a greater degree of syntactic disjointness, and finite differentiation in its compositional schemes (constructing combinations of sounds with some possibilities for establishing notational systems). ${ }^{36}$

Using his recasting of the characteristics of art symbols, Goodman identifies three distinct forms of reference applicable to art symbols: representation, expression, and exemplification. Representation, he argues, is a matter of habit and familiarity rather than being based on natural resemblance. Understanding what a picture represents is a matter of invoking a range of cognitive resources including discerning its pictorial properties in reference to pictorial conventions and may involve complex connections to historical, scientific or mythical refer-

35 Goodman (1968).

36 Goodman (1978b), 179-198. 
ences. ${ }^{37}$ Exemplification is symbolizing by means of sample; it refers to the relation between a sample and the features in its referents. For example, a musical work might exemplify its harmonic or rhythmic properties. Or a painting might exemplify its colors, shapes, or textures. Familiarity with the symbol system in question is necessary to identifying the properties being exemplified. Artistic symbols according to Goodman, can exemplify only those properties they actually possess. Expression, the third form of reference in Goodman's account of symbols, entails metaphorical exemplification. For example, a painting, which is not literally expressing sadness, may metaphorically express the feeling of sadness.

While introducing a radically new form for understanding art symbols with considerably more detailed features than were offered by Cassirer or Langer, Goodman also tackles other central problems in aesthetics. For example, he replaces the question, "what is art?" with the question, "when is art?" In addition, he supplants aesthetic properties as the means of identifying art. Instead he substitutes the various syntactic and semantic properties operative in the respective art forms. As well, Goodman dismisses the relevance of artists' intentions. Gone too are attempts to proffer spurious distinctions between scientific understanding and art. For Goodman, they represent two complementary means for making and understanding our worlds. Similarly, art and philosophy are complementary means of world making; a claim that Goodman set out to demonstrate in actually creating a notable dance-theater work, Hockey Seen. Hockey Seen incorporates dance, theater, music, drawings, costumes, theater design, and elements from a hockey game with ideas contributed by Goodman. ${ }^{38}$ His aim in this work was to present an application of his philosophical theories expressed in Languages of Art in the making of an actual work.

\section{Art and the Philosophy of Art Symbols}

Perhaps it is useful to conclude this discussion with some questions. First is the question concerning what motivated these philosophers to push beyond ideas their predecessors had offered concerning art's place in human understanding? No doubt these efforts were substantially driven substantially by their interest in addressing, and hopefully solving, the puzzles raised by art as a form of human symbolic activity in relation to language and the sciences. We find cumulative references in all three of our candidates presented here to the philosophical

37 Goodman (1988).

38 Carter (2009). 
groundings for addressing the problems in their respective predecessors running from Plato to their contemporaries. As we have seen, for Cassirer the main sources of understanding problems in aesthetics were Vico, Kant, and Hegel. For Langer, the sources were symbolic logic, Cassirer's philosophy of symbols, and the biological sciences. For Goodman, Cassirer's views on the role of symbols in worldmaking and his interest in symbolic logic, especially Carnap's ideas provided useful starting points for his investigations into the philosophy of symbols. ${ }^{39}$

I would like to propose that the concurrent changes in the arts developing during the lives of the three philosophers' explorations of art's role in cognition, and its relation to other forms of symbols, may have provided additional incentive for their interest in championing the importance of art symbols. Goodman, for example was an avid collector of art including modern art, as well as Seventeenth Century Dutch, and art from China, India and American tribal arts. Between 1928 and the early 1940's he ran an art gallery in Boston. In addition to Hockey Seen, Goodman's most ambitious venture into the arts, he initiated projects relating to music, dance, and Picasso's art, over the course of his life.

The art of the era during which our three aestheticians formulated their views concerning art symbols contrasts sharply with the representational art epitomized in Goethe's elegant tribute to the artist Caspar David Friedrich noted at the beginning of our discussion.

Following the invention of photography some fifty years earlier, the artists of the twentieth century continued to invent new forms of art. In the words of the eminent twentieth century art historian Meyer Shapiro,

... The ideal of an imageless art of painting was realized for the first time, and the result was shocking-an arbitrary play with forms and colors that had only a vague connection with visible nature. Some painters had discovered that by accenting the operative elements of art-the stroke, the line, the patch, the surface of the canvas-and by disengaging these from the familiar objects altogether, the painting assumed a more actively processed appearance, the aspect of a thing made rather than a scene represented, a highly ordered creation referring more to the artist than to the world of external things. ${ }^{40}$

One outcome of these developments was the notion that the aim of art need not be narrating a story or copying nature, but rather to "express a state of feeling,

39 Apart from the citations noted in footnote 33, the extent of Goodman's connection with Cassirer is not known. Catherine Elgin, Goodman's colleague and co-author, reported that she did not recall Goodman's having discussed Cassirer's work during their association.

40 Shapiro (1978), 142. 
an idea...or to create a harmony of colors and forms". ${ }^{41}$ This shift corresponds to the view shared by Cassirer and Langer that art is a means of expressing inner feelings or ideas as well as their common task of studying the forms of consciousness or unconsciousness that generate them. The shift also is consonant with Goodman's view that art participates in the cognitive contributions to understanding.

The art and the theories of the Russian-born Wassily Kandinsky (1866-1944) will serve to illustrate the changing climate for art during the period in question. In an invitation issued to artists in 1909 announcing the formation of a "New Association for Artists of Munich", Kandinsky states, "Our point of departure is the thought that the artist, in addition to the impressions he received from the external world, from nature, continuously collects experiences in an inner world". ${ }^{42}$ Perhaps reflecting Hegel's view "of a necessary perpetual spiritual progression away from dependence on the external world", Kandinsky argues in his book, Concerning the Spiritual in Art for a principle of "inner necessity" that would liberate art to establish a new aesthetic of symbols emphasizing inner feelings and artistic form over representation of the external world. Kandinsky's view did not exclude impressions from the external world, but his ideas and artistic practice clearly places the focus on art's origins in the inner life of the artist. ${ }^{43}$

While one cannot cite direct contact between Cassirer and Kandinsky, it seems plausible to suggest that a prominent philosopher interested in art, and living in Germany during the first decades of the twentieth century, would be aware of innovative artistic developments taking place there. Kandinsky developed as an artist while living in Munich between 1896 and 1914, and at the Bauhaus (first in Weimar then in Dessau and finally in Berlin) between 1922 and 1933, the leading site of innovative development in the arts in Europe at the time.

In particular, artists' shift from images linked to external reality in the Twentieth century, including nature, to images originating in the inner life of individual artist's called for explanation not available in traditional rationalist aesthetics. ${ }^{44}$ The seeming formless expressions of feelings and the plethora of newly invented forms now appearing in art invited new investigations in aesthetics of the sort undertaken by Cassirer and later by Langer and Goodman.

Correspondence, if not causal connections between the interests of our philosophers considered here, and the developing shift in the practices of art from representation to abstraction and expression, is a subject calling for further in-

41 Ibid.

42 Kandinsky (1909), 67.

43 Heller (2003), 68.

44 Shapiro (1978), 145-146. 
vestigation. In any event, the shift in art practices exhibited in Kandinsky's art and other modern artists corresponds nicely with the shifting focus of aesthetics from representational theories to expressionist theories and leading to philosophies of art symbols such as those under consideration in our discussion here.

Such radical developments in art and aesthetics inevitably raised new questions. Were these new developments to be interpreted as a sign of a deteriorating culture, hence warranting hostility to the novelties of modern art and philosophy, and, deservedly, their being subjected to criticism? Or might these changes signal that new developments in art and philosophy, as in physical science and technology, are necessary components of an invigorative society?

One difference between art and philosophy is that art generates personal responses through which one identifies with, or rejects particular works of art on the basis of personal feelings. This is not necessarily the case in philosophy or in science and technology where the acceptance and the uses of products and ideas does not depend as much on personal feelings as in changes of outlook. Hence, there is an even greater need for aesthetic theories that will help to assimilate new artistic developments into the understanding of individuals, clarify art's societal roles, and sustain art's place in the on-going stream of philosophical and other cultural investigations.

This discussion brings us to the second set of questions: How have the reflections on symbolic forms in the writings of Cassirer, Langer, and Goodman contributed to these undertakings? Without implying that each had the exact same aims in their treatments of symbolic forms, I conclude that they are all working toward a similar end of clarifying the nature, types, and functions of particular symbolic forms. Cassirer effectively presents the argument that symbols are the means by which humans form their conceptual worlds, and he perceives the importance of recognizing differences between art and the other symbol systems that contribute to this task of worldmaking. He finds the origins of art symbols in imagination or intuition, but does not fully account for the variations in how or why the symbols operative in art and elsewhere differ, apart from noting differences in their functions. Langer and Goodman carry on this project introducing further distinctions among the types of symbols and the ways in which they function based on their logical features. Each of these philosophers has at least made a strong case for the continuing relevance of art as an important means of constructing and understanding our worlds. Together they have shown that art symbols contribute an enriching form of symbolism to human understanding, essential and complementary to language, the sciences, and other forms of symbols. 


\section{Bibliography}

Capeillères (2008): Fabien Capeillères, "Art Esthetique et Geisstgechichte: Appropos des Relations entre Warburg, Cassirer et Panofsky", Cassirer Studies I (2008), 77-100. Capeillères (2009): Fabien Capeillères, “' $\mathrm{K}$ ' for 'Kunst'. Cassirer's Pages on Art for PRs IV with a note on Francis Bacon", Cassirer Studies II (2009): 11-50.

Capeillères (2011): Fabien Capeillères, “Art Critique as a Philosophical Science?”, Cassirer Studies IV (2011), 65-81.

Capeillères (2013): Fabien Capeillères, “Artistic Thinking within Cassirer’s System of Symbolic Forms: A Brief Reassessment”, unpublished paper presented at The Seminar on Aesthetics symposium, "Cassirer and the Aesthetic-Expression, Representation, Significance", University of Oslo, February 28, 2013

Carter (1974): Curtis L. Carter, "Langer and Hofstadter on Painting and Language: A Critique", Journal of Aesthetics and Art Criticism 32 (1974), 331-342.

Carter (2009): Curtis L. Carter, “Nelson Goodman's Hockey Seen: A Philosopher's Approach to Performance", Congress Book II, XVII International Congress of Aesthetics, Jale Erzen (ed.), Sanart, 60-67.

Cassirer (1946): Ernst Cassirer, Language and Myth, Susanne Langer (trans.), New York: New York: Harper and Brothers.

Cassirer (1949): Ernst Cassirer, “'Life' and 'Spirit' in Contemporary Philosophy”, R. W. Bretall and P. A. Schilpp (trans.), in: The Philosophy of Ernst Cassirer (Library of Living Philosophers, 6), P. A. Schilpp (ed.), LaSalle, IL: Open Court Publishing Company, 855-880.

Cassirer (1956): Ernst Cassirer, An Essay on Man, New York: Doubleday \& Company. Cassirer (1979a): Ernst Cassirer, "Language and Art I", in: Donald Phillip Verene (ed.), Symbol, Myth, and Culture: Essays and Lectures of Ernst Cassirer 1935-1945, New Haven and London: Yale University Press.

Cassirer (1979b): Ernst Cassirer, "Language and Art II", in: Donald Phillip Verene (ed.), Symbol, Myth, and Culture, op. cit.

Cassirer (1979c): Ernst Cassirer, “The Educational Value of Art", in: Donald Phillip Verene (ed.), Symbol, Myth, and Culture, op. cit.

Cassirer (1996): Ernst Cassirer, Philosophy of Symbolic Forms, Volume Four: The Metaphysics of Symbolic Forms, J.M. Krois/D. P. Verene (eds.), New Haven: Yale University Press.

Gilbert (1949): Catherine Gilbert, “Cassirer's Placement of Art”, in: P.A. Schilpp (ed), The Philosophy of Ernst Cassirer, op. cit.

Goethe (1980): J.W. von Goethe, “Caspar David Friedrich”, in: John Cage (ed.), Goethe on Art, Berkeley and Los Angeles: University of California Press.

Goodman (1951): Nelson Goodman, The Structure of Appearance, Cambridge, MA: Harvard University Press.

Goodman (1968): Nelson Goodman, “Art and Inquiry”, Proceedings of the American Philosophical Association, Eastern Division, 5-19.

Goodman (1972): Nelson Goodman, Problems and Projects, Indianapolis: Bobbs Merrill Company.

Goodman (1978a): Nelson Goodman, “Words, Works, Worlds”, in: Ways of Worldmaking, Indianapolis: Hackett Publishing Company, 1-22.

Goodman (1978b): Nelson Goodman, Languages of Art, Indianapolis: Bobbs Merrill Company. 
Goodman (1988): Nelson Goodman, “Confronting Novelty", in: Reconceptions in Philosophy \& Other Arts \& Sciences, Indianapolis and Cambridge: Hackett Publishing Company. Heller (2003): Reinhold Heller, "The Blue Rider", in: Schoenberg, Kandinsky, and the Blue Rider, Esther da Costa Meyer and Fred Wasserman (eds.), New York and London: Scala Publishers, 2003.

Hendel (1955a): Charles W. Hendel, “Introduction”, in: Ernst Cassirer, Philosophy of Symbolic Forms, Volume I, New Haven: Yale University Press.

Kandinsky (1909): Wassily Kandinsky, 1909 Invitation, New Association of Artists Munich, as cited in: Reinhold Heller, “The Blue Rider", op. cit.

Langer (1950): Susanne Langer, "The Principles of Creation in Art", The Hudson Review 2 (No. 4), 515-534.

Langer (1962a): Susanne Langer, “On a New Definition of Symbol”, in: Susanne Langer (ed.), Philosophical Sketches, Baltimore: Johns Hopkins Press.

Langer (1962b): Susanne Langer, “The Cultural Importance of Art”, in: Philosophical Sketches, op. cit.

Langer (1967a): Susanne Langer, Mind: An Essay on Human Feeling I, Baltimore: The Johns Hopkins Press.

Langer (1967b) Susanne Langer, Philosophy in a New Key, Cambridge, MA: Harvard University Press; original publication 1942.

Scheffler (1985): Israel Scheffler, "The Wonderful Worlds of Goodman", in: Inquiries: Philosophical Studies of Language, Science and Learning, Indianapolis: Hackett Publishing Company.

Shapiro (1978): Meyer Shapiro, Modern Art: $19^{\text {th }}$ and $20^{\text {th }}$ Centuries; Selected Essays, New York: George Braziller.

Slochower (1949): Harry Slochower, “Ernest Cassirer's Functional Approach to Art and Literature", in: P.A. Schilpp (ed.), The Philosophy of Ernst Cassirer, op. cit.

Verene (1979): Donald Phillip Verene, "Introduction”, in: Symbol, Myth, and Culture: Essays and Lectures of Ernst Cassirer 1935-1945, op. cit. 